\title{
Rational Thinking on Bioethics Education for Students in Public Security Colleges
}

\author{
Surpassing Life
}

\author{
Jun Lu \\ Sichuan Police College \\ Sichuan, China 646000
}

\begin{abstract}
According to group characteristics of students in public security colleges, life education on them is analyzed from the perspective of ethic, and paths to solve the predicaments of bioethics education for these students are explored, in order to guide them to establish correct outlook on bioethics and positive outlook on life and values.
\end{abstract}

Keywords-students in public security colleges; bioethics education; paths

\section{INTRODUCTION}

At present, most researches on college students' life education analyze the significance, connotation and ways of college students' life education from the perspectives of ideological and political education, sociology, pedagogy and psychology. However, it discusses on theoretical level instead of college students' bioethics education and fails to form systematic, theoretical and efficient patterns of bioethics education. Like students in other colleges, although students in public security colleges have rational knowledge on life, some fail to understand the significance of life existence especially lack enthusiasm in pursuing life value. The talent training objectives with prominent politics, discipline and stringency and management pattern in public security colleges make students have group characteristics different from students in other colleges. The bioethics education for students in public security colleges under the pattern of vocational education lags behind. Therefore, it is the requirement of occupational awareness education in colleges of special industry and comprehensive development of students in public security colleges to strengthen bioethics education.

\section{II. “PRIMITIVE” APPEAL OF BIOETHICS EDUCATION FOR STUDENTS IN PUBLIC SECURITY COLLEGES}

Undoubtedly, the pursuit of life essence is the theoretical basis of research on bioethics education. We must first clearly define the meaning of life, the connotation of bioethics and basic contents of bioethics education in order to find methods and solve problems in bioethics education for students in public security colleges. First, what is life? In broad sense, in Weber Encyclopedia, life refers to biology with ability of metabolism and reproductive capacity. In narrow sense, life only refers to human life. Life has three characteristics: it has close relationship with other individuals; it has an internal complete structure; it reaches self-actualization or self-improvement of higher forms through continuous self-transcendence. [1] Therefore, life mentioned in this paper refers to people with vital signs in society. Second, bioethics refers to the moral rules and principle system follow by people who face environment, themselves and life value and dignity of other life entities. In educational circles, bioethics means carrying out moral examination of people's life state; the ethical study on ultimate question of life; ethical judgment and reflection on life sciences and biotechnology; moral philosophy interpretation of nature, value and meaning of life especially human life. [2] Comply with theoretical inheritance and connotation explanation. Third, we think bioethics education is the process to read and feel life essence of individuals, improve life dignity, explain life value and pursue the meaning of life. The bioethics education on college students means understanding, realizing and sublimating life development. It uses the wisdom of bioethics to improve the quality of life existence. Bioethics education is selfunderstanding of life culture, lets college students form correct outlook on life and values and consciousness and concept of reverencing, cherishing and caring for life and becomes the consciousness of college students' life culture. [3] Some think that bioethics education is to help people understand life is valuable and unique, understand life value and experience the meaning of life, make personality perfect, realize life value and pursue the truth of life. Therefore, bioethics education of colleges is by no means the teaching and learning of life knowledge in general sense, but the moral education on life care, and the connotation improvement of moral education in colleges. Morality derives from people's needs of life to make people's life happy. Therefore, bioethics education of colleges must focus on people's life. It is neither teaching of life knowledge nor compulsion on students to let them accept outlook on life passively, but equal communication. It requires students to understand life, the life value of human and the meaning of life and stick to life spirit, stimulates students to pursue the ultimate life belief, develops students' loving care and arouses their perception of life potential and self-confidence and lets them reverence life. In the harmonious communication with life language, students can learn the meaning and value of life and establish correct values. 
All in all, we can define bioethics education for students in public security colleges as the ethical moral education that starts from the life existence of individuals, bases on the construction of world with the value and meaning of life, uses harmonious, equal and interactive, efficient educational methods to guide college students to correctly grasp the connotation of life, face predicaments in life, follow the nature of life, understand the existing significance of life, trains their reverence for life, in order to organically integrate morality with life and influence the soul of life.

\section{ANALYZE THE "REALITY" OF BIOETHICS EDUCATION FOR STUDENTS IN PUBLIC SECURITY COLLEGES}

In the new era, students in public security colleges have clear and correct understanding of life and the value and meaning of it, and the most active thoughts. But they also face diversified troubles in mind and realistic problems because of the earth-shaking changes of social environment and changes of individual psychology, leading to anti-life behaviors and phenomenon. Nowadays, students in public security colleges still lack the atmosphere of ethical care of life, correct life education and effective ways in bioethics education.

First, the training objectives fail to pay attention to college students' life and construct the world with meaning of life. The occupational education focuses on students' political consciousness and ideal and separates from students' life state in reality. It tells students to forget about their own and have the courage to sacrifice but fails to tell them the meaning of life for themselves, family, friends and society, let along guiding students to explore and think about the meaning of life and establish correct life values.

Second, the management layer of schools pays inadequate attention to bioethics education. Although the absence of bioethics consciousness of students in public security colleges has caused widespread concern of schools, the management layer fails to correctly realize the urgency of bioethics education. Under the influence of traditional educational concepts that value specialty, knowledge teaching and skill training, they use the deficiency of professional teachers as an excuse. As a result, like other humanities, the bioethics education becomes formalistic and lacks effectiveness.

Third, the contents of bioethics education are simple. At present, few public security colleges offer courses related to bioethics education. Most of them still teach knowledge of life value in traditional ideological and political theory course to carry out bioethics education. It is far from adequate, neither meeting students' demands for knowledge of bioethics nor making students clearly understand bioethics. The consequence is that students' emotions, souls and personalities depend on the uniform political education. Some college students are indifferent and dissocial and lack life emotion, even doubt the meaning and value of life, so that they are deep in crisis of spiritual lost and fail to feel the value and meaning of life.

Last, the mechanism of bioethics education is unsound and educational methods are simple. The mechanism construction of bioethics education in public security colleges is in the early stage, lacking professional teachers, resource integration and platform construction. Bioethics educators cannot get attention and lack enthusiasm in work so that they muddle through their work inevitably. Facing college students' anti-life behaviors, public security colleges always guide through psychological consulting of professional psychology teachers or one-to-one ideological and political education. It is effective to some extent but the teaching method is backward and cannot solve the fundamental problem that students lack bioethics consciousness.

\section{EXPLORE PATHS THAT THE BIOETHICS EDUCATION FOR STUdENTS IN PUbliC SECURITY COLLEGES "SHOULD FOLLOW"}

At present, according to anti-life behaviors of students and the unpromising situation of bioethics education in public security colleges, it requires us to face the problem in bioethics education, further strengthen and improve bioethics education and guide students to establish the ethical thoughts and modern bioethics values of loving and reverencing life and pursuing the meaning of life.

\section{A. Base on the Reality of Life and Reflect on Life}

Students face two major problems in reality, the imbalance of ideal and reality, and the contradictions between emotional needs and reality. The intersection of the two problems is the problem of difficult real life and the problem of correctly understanding life essence. Students may trample life if they are bothered by them. Therefore, it is important for bioethics education to solve the problem that how students in public security colleges to get moral humanistic care and life comfort to explain the strained relations among life, society and living. Reflect on the wisdom of life that comes from life, the experience of life emotions and ethical reflection of surpassing life. Firstly, offer courses related to bioethics education. Schools should think about the objectives, contents and ways to offer these courses and explore effective educational contents and ways to let students acquire the wisdom of bioethics. It is important to let college students acquire the wisdom of bioethics through adding cases of "dilemma" about life and death. Students are guided to cherish life, pursue the value and meaning of life, develop optimistic attitudes toward life, respect the existence of others, treat others and themselves kindly through discussion on specific cases of "dilemma" in real life and philosophical analysis on life and death in some cases. Secondly, invite medial staff to narrate death cases in class, strengthen students' life emotion and teach students the countermeasures when facing natural and man-made disasters and sudden changes of life style and the methods to control emotions in extraordinary case. Finally, make the best of carriers of bioethics education like funeral parlor and let students experience the meaning of life existence. Individual experience of disappearance of life in reality is enough to make students reflect on the meaning and value of living life. Thinking on disappearance of individual life can strengthen students' understanding of death and survival, let 
them understand life value, reconstruct life order, and pursue the eternity of life.

\section{B. Develop Professional Role and Make the Consciousness of Asserting Lift Rights Firm}

Police is a specific professional role in society. Morality and law stipulates the obligation and responsibility of them. Most students in public security colleges work in Public Security Bureau, court and procuratorate after graduation. The bioethics education should train college students' legal thinking to assert life rights and make firm consciousness of professional role. As probationary police officers, they should establish the concept that life and death are independent of man's will and have the obligation to perform their duties when they need to dominate the life rights for national interest, collective interest even the interest of others.

\section{Cultivate Consciousness of Responsibility and Cherish Life Existence}

Marx and Engels once proposed when discussing general responsibility of people that "No matter whether you realize, as certain people in reality, you must have regulations, life and tasks". That is to way, responsibility embodies social inevitability of people and everyone is "inescapable". [4] It is urgent and important to train the consciousness of students in public security colleges of life responsibility in bioethics education because people who have responsibility for life will not treat life with indifference and trample life. The bioethics education in public security colleges must train probationary police officers' consciousness of professional role about "who I am" and cultivate vocational responsibility, so that students will treat life with justice and equity in lawenforcement practice and fully embody social justice.

\section{Cultivate the Consciousness of Reverencing Life and Sublimate Life Value}

The concept of reverence for life embodies in the thought of "valuing life" in the traditional ethnical culture in our country. Traditional life thoughts such as "My body, including hair and skin are given by my parents and we must cherish and protect it, and it is the essence of filial piety", "People are the most precious", "People with faith are praiseworthy" embody life value and outlook on life closely related to moral principles. The nature of reverence for life is to reverence the value and meaning of life. People who reverence life will respect life. For example, the thought of "knowing the fate decreed by Heaven" said by Confucius can be regarded as a dynamic outlook on life instead of attempting and accomplishing nothing. It means behaving and handling affairs with awe-stricken psychology, shouldering and performing responsibilities to pursue the meaning and value of life. The humanistic value and spiritual rational return in traditional precious thoughts of bioethics can enlighten college students to treat individual life from the ethical vision, enrich and understand the connotation of life with strong sense of reverence for life. Therefore, they will respect life, care for others and the society, treat their fate with positive and responsible attitude and deal with the relations among people, society and nature, finally deeply concern and firmly fulfill life essence.

\section{CONCLUSION}

To sum up, bioethics education for students in public security colleges is a long-term and arduous systems engineering, to which the management layer of public security colleges and bioethics educators should pay attention. They establish correct training objectives of bioethics education, excavate, use and integrate life education resources in school, enrich forms and contents of bioethics education for college students, and expand platform and carrier as well as improve mechanism of bioethics education, in order to guide students to form positive bioethics concept and promote the integrated development and growth of students in public security colleges.

\section{REFERENCES}

[1] Mei Ping. Research on Bioethics Education for Contemporary College Students [M], China Social Sciences Publishing House, 2009

[2] Ma Wenyuan, Zheng Lijuan, Tong Chuanguang. Bioethics [M], Dalian: Liaoning Normal University Press, 2006

[3] Luo Jun. Looking Bioethics Education for Contemporary Students from the Perspective of "Cat Abused Incident" [J], Study Monthly, 2007, (06)

[4] Wang Xiaohong. Moral Responsibility: Key Point of Connotation of Moral Education in Colleges [J], Journal of Jiangxi Science and Technology Normal University, 2004(3) 